\title{
Preferencia de hospedantes por dos biotipos de Bemisia tabaci en Costa Rica y Florida ${ }^{1}$
}

\section{Host preference by two Bemisia tabaci biotypes in Costa Rica and Florida}

\author{
Luko Hilje ${ }^{2}$, Philip A. Stansly
}

\begin{abstract}
Resumen
Bemisia tabaci (Gennadius) muestra una gran polifagia, pero también una marcada preferencia por ciertos hospedantes, lo cual puede depender del biotipo específico involucrado. El objetivo de la presente investigación fue comparar la preferencia hacia un grupo selecto de cultivos hospedantes, por parte de dos biotipos de Bemisia tabaci, el New World en Costa Rica, y el MEAM1 en Florida. Para ello, se realizaron experimentos de preferencia, en invernaderos, tanto en Turrialba (Costa Rica) como en Immokalee (Florida), en abril y junio-setiembre de 1998, respectivamente. Se expusieron los mismos cultivos y variedades a los biotipos New World y MEAM1, predominantes en cada una de esas localidades, respectivamente. Se incluyeron la vainica (Phaseolus vulgaris), el chile dulce (Capsicum annuum), la berenjena (Solanum melongena), el pepino (Cucumis sativus), el tabaco (Nicotiana tabacum) y el tomate (Solanum lycopersicum). Los potes con plántulas de cada uno de los hospedantes se colocaron sobre el piso del invernadero, espaciados entre sí. Se liberaron los adultos de $B$. tabaci en el área experimental, y después se registraron los números de individuos en cada planta. En Turrialba el tabaco fue el cultivo preferido por el biotipo New World, seguido por la berenjena, mientras que en Florida el biotipo MEAM1 prefirió la vainica y la berenjena. No obstante, a pesar de estas diferencias, ambos biotipos exhibieron una fuerte y significativa preferencia por la berenjena, lo cual abre la posibilidad para su utilización como cultivo trampa.
\end{abstract}

Palabras clave: tomate, tabaco, berenjena, Aleyrodidae.

\begin{abstract}
Despite being a polyphagous insect, Bemisia tabaci (Gennadius) shows a marked preference for certain hosts, which in turn may depend upon the particular whitefly biotype involved. The objective of this research was to compare preference towards a selected group of host crops, by two biotypes of Bemisia tabaci, New World in Costa Rica, and MEAM1 in Florida. Therefore, choice experiments were conducted in greenhouses both at Turrialba (Costa Rica) and Immokalee (Florida), in April and June-September, 1998, respectively. The same crops and varieties were exposed to the New World and MEAM1 biotypes, which predominate in each one of these locations, respectively. Host species included green beans (Phaseolus vulgaris), bell pepper (Capsicum annuиm), eggplant (Solanum melongena),
\end{abstract}

\footnotetext{
Recibido: 20 de diciembre, 2017. Aceptado: 4 de abril, 2018. Este trabajo fue producto del proyecto Development of crop associations for managing geminiviruses vectored by whiteflies in tomatoes (FG-CR-108, CS-AES-7), financiado por el Departamento de Agricultura de Estados Unidos (USDA) y coordinado por el Centro Agronómico Tropical de Investigación y Enseñanza (CATIE), en Turrialba, Costa Rica.

2 Centro Agronómico Tropical de Investigación y Enseñanza (CATIE), Turrialba, Costa Rica. luko@ice.co.cr

3 University of Florida-IFAS, Southwest Florida Research \& Education Center (SWFREC), Immokalee, Florida 34142, United States. pstansly@ufl.edu
} 
cucumber (Cucumis sativus), tobacco (Nicotiana tabacum) and tomato (Solanum lycopersicum). Seedlings were transplanted in large pots, which were distributed on the greenhouse floor. B. tabaci adults were released in the late afternoon, and the number of individuals on each plant was recorded the next morning. In Turrialba, tobacco was greatly preferred by New World biotype adults, followed by eggplant, whereas the MEAM1 biotype in Florida preferred green beans and eggplant. Thus, both biotypes showed a strong and significant preference for eggplant, which suggests its possible utility as a trap crop.

Key words: tomato, tobacco, eggplant, Aleyrodidae.

\section{Introducción}

La mosca blanca Bemisia tabaci (Gennadius) (Hemiptera: Aleyrodidae) es considerada una de las plagas más importantes en el plano mundial. En zonas tropicales y subtropicales puede causar daño en numerosos cultivos, tanto de exportación como de consumo doméstico, ya sea por sus altas poblaciones o como vector de una gran diversidad de virus, sobre todo begomovirus, de la familia Geminiviridae (Anderson y Morales, 2005).

En América Central y el Caribe, al igual que en Florida, un cultivo tan importante como el tomate puede ser seriamente afectado por varias especies de begomovirus. De ellos, en Costa Rica, predominaban el Tomato yellow mottle virus (ToYMoV) y el Tomato leaf curl Sinaloa virus (TLCSiV) (Morales et al., 2005), pero poco a poco han sido desplazados por el Tomato yellow leaf curl virus (TYLCV) (Barboza et al. 2014); asimismo, el Tomato Mottle Virus (ToMoV) fue desplazado por el TYLCV en Florida. El TYLCV, común en ambas regiones, es de origen israelí y tiene varias cepas, que se han diseminado ampliamente (Lefeuvre et al., 2010). En este trabajo se utilizan sus nombres en inglés, según los acuerdos internacionales de nomenclatura de virus (Brown et al., 2015); el ToYMoV no se escribe en cursivas, por no estar oficializado aún.

Desde que el TYLCV se detectó en Costa Rica en 2012, se ha reducido de manera notable la producción comercial de tomate, tanto en el Valle Central como de la región occidental del país (Barboza et al., 2014), debido a que puede causar aborto floral. A su agresividad, debe sumarse la gran plasticidad genética del vector, pues se conocen al menos treinta biotipos o razas de B. tabaci, que no se pueden distinguir una de otra. En el caso de Costa Rica, hasta hace pocos años predominaba el biotipo A, pero en años recientes se detectaron el B y el Q (Morales et al., 2005; Hernández et al., 2014); los dos últimos se han extendido de manera gradual por el país, e incluso han desplazado al primero, pero determinar su actual distribución requiere estudios detallados y una alta inversión monetaria. Por su parte, en Florida el TYLCV ha estado presente desde 1997, y ha continuado su expansión gracias a ambos biotipos, de los cuales el biotipo Q ingresó en 2005 (McKenzie et al., 2009).

La existencia de tantos biotipos de $B$. tabaci, ha causado mucho debate entre los investigadores desde hace aproximadamente dos decenios, lo cual ha dado origen a numerosas revisiones y publicaciones. No obstante, en la búsqueda de consenso, en años recientes a algunos biotipos se les ha reconocido incluso como especies diferentes, a las que se les ha denominado con un código tentativo, referido a su origen geográfico, mientras se les describe como especies diferentes (Boykin, 2014). Los respectivos nombres y siglas de los biotipos A, B y Q son New World, Middle East Asia Minor (MEAM1) y Mediterranean (MED), que en español corresponden a Nuevo Mundo, Medio Este-Asia Menor y Mediterráneo. Esta será la nomenclatura empleada en este artículo.

Ante tan compleja y amenazante situación del TYLCV y los biotipos de mosca blanca para los productores de tomate y de otros cultivos anuales, es necesaria la búsqueda de métodos preventivos, enmarcados en la noción del manejo integrado de plagas. Una de las posibles formas de abordar su manejo es evitar que el vector inocule las plantas de tomate durante el período crítico, cuando éstas son más susceptibles; dicho intervalo comprende las primeras ocho semanas desde la germinación, aproximadamente (Schuster et al., 1996). Durante el período crítico, la inoculación 
de las plantas podría evitarse o reducirse mediante algunas prácticas agrícolas de eficacia demostrada, o al menos promisorias (Hilje et al., 2001). Una de ellas son los cultivos trampa, que han recibido amplia atención en el campo entomológico (Hokkanen, 1991; Shelton y Badenes-Perez, 2006), y cuyo fundamento biológico es la "distracción" o desvío del insecto plaga hacia un cultivo de importancia secundaria o nula para el agricultor, y sembrado de manera deliberada con esa intención.

En el caso particular de B. tabaci, al establecer cultivos trampa se han efectuado muy pocos esfuerzos en varios países y con resultados prometedores pero variables. Entre los tipos de asociaciones investigadas, y acerca de las cuales se han publicado artículos formales, figuran el maíz, caupí y maní intercalados con yuca (Fargette y Fauquet, 1988; Ahohuendo y Sarkar, 1995); melón con algodón (Castle, 2006); calabaza con arveja (Smith et al., 2000); y berenjena con frijol común (Smith y McSorley, 2000). En el caso del tomate, se le ha intercalado con vainica (Arias y Hilje, 1993; Peralta y Hilje, 1993) y con calabaza (Schuster, 2004).

Para el manejo de B. tabaci en tomate en sus zonas de interés inmediato, Costa Rica y Florida, se propone sembrar un hospedante (cultivo o planta silvestre) que sea más atractivo que el cultivo principal, para que el vector se dirija hacia él, al cual se le aplica un insecticida sistémico o un hongo entomopatógeno, con el fin de eliminar a los adultos virulíferos antes de que inoculen los virus en el tomate. Sin embargo, sería esperable que la preferencia del vector dependiera del biotipo al que pertenece (De-Barro et al., 2011). Al respecto, cuando se efectuó este estudio, en Costa Rica predominaba el biotipo New World, y posiblemente esto siga teniendo validez, mientras que el MEAM1 era el único detectado en Florida.

El objetivo de la presente investigación fue comparar la preferencia hacia un grupo selecto de cultivos hospedantes, por parte de los biotipos New World en Costa Rica y el MEAM1 en Florida.

\section{Materiales y métodos}

\section{Experimento con el biotipo New World (Costa Rica)}

El experimento con el biotipo New World se efectuó en abril de 1998 en un invernadero de la Unidad de Fitoprotección, en el Centro Agronómico Tropical de Investigación y Enseñanza (CATIE), en Turrialba. El CATIE se ubica en la vertiente del Caribe de Costa Rica, a 09² $52^{\prime} \mathrm{N}, 83^{\circ} 38^{\prime} \mathrm{O}$ y $590 \mathrm{~m}$ de altitud.

Se utilizó un diseño completamente aleatorizado, dadas las condiciones homogéneas en el invernadero y el pequeño espacio ocupado por el experimento. Hubo seis tratamientos, con cuatro repeticiones cada uno, y cada experimento se replicó cuatro veces, en días consecutivos, aleatorizando los tratamientos. Estos fueron: vainica (VA) (Phaseolus vulgaris, Fabaceae), chile dulce (CD) (Capsicum annuum, Solanaceae), berenjena (BE) (Solanum melongena, Solanaceae), pepino (PE) (Cucumis sativus, Cucurbitaceae), tabaco (TB) (Nicotiana tabacum, Solanaceae) y tomate (TO) (Solanum lycopersicum, Solanaceae).

Plántulas (con tres hojas verdaderas) de vainica (variedad Provider), chile dulce (variedad Agronómico 10), berenjena (variedad Black-Peruti), pepino (variedad Poinsett 76), tabaco (variedad Jaltepec) y tomate (variedad Hayslip), fueron trasplantadas de manera individual en potes plásticos negros de 10,5 1 (No. 1200), con suelo esterilizado en un horno. Los potes se colocaron sobre el piso del invernadero, espaciadas $40 \mathrm{~cm}$ entre sí. El área foliar $\left(\mathrm{cm}^{2}\right)$ se determinó para plantas completas, midiendo hoja por hoja, mediante un medidor de áreas AM100.

Los adultos de B. tabaci se recolectaron con un aspirador manual, en una colonia criada sobre plantas de tomate en un invernadero aledaño. Se liberaron 1200 individuos en el área experimental la víspera de cada experimento, a las 15-16 h, para que se habituaran al sitio y se posaran en las plantas elegidas. Fueron separados en seis grupos (de 200 adultos), cada uno colocado en un frasco plástico transparente, el cual se sujetó con una banda de hule a un poste de metal de $1 \mathrm{~m}$ de altura. Los seis postes se distribuyeron de manera uniforme en el área experimental para evitar sesgos. 
Se registró el número de adultos en cada hospedante, entre las 8:30 y las 10:30 h, antes de que se presentara el principal pico de vuelo que ocurre diariamente (Jovel et al., 2000), el día de cada experimento. Para ello, se muestreó cada planta mediante una trampa, que consistió en un balde negro grande (de $34 \mathrm{~cm}$ de diámetro), invertido y colocado sobre cada maceta; este tenía un pequeño frasco en la parte superior y una manga lateral de manta. Una vez colocado sobre la respectiva planta, a través de la manga, se introdujo la mano del observador para agitar la planta, de modo que los adultos huyeran y se introdujeran en el frasquito, para ser contados, una vez anestesiados en el laboratorio. Al finalizar cada experimento, cualesquiera adultos remanentes se recolectaron, para evitar sesgos en los recuentos de los experimentos de los días siguientes.

Los datos se sometieron a un análisis de varianza de parcelas divididas, donde los tratamientos (hospedantes) se consideraron como la parcela principal y el tiempo (fechas) como las sub-parcelas. Las medias fueron comparadas mediante la prueba de Tukey (SAS Institute, 1985), con un nivel de significancia de 0,05. Asimismo, se realizaron los siguientes contrastes ortogonales: tomate $v s$. resto de tratamientos, tomate $v s$. resto de Solanaceae, todas las Solanaceae $v s$. vainica, todas las Solanaceae vs. pepino, tabaco vs. resto de Solanaceae (SAS Institute, 1985).

\section{Experimento con el biotipo MEAM1 (Florida)}

El experimento con el biotipo MEAM1, se realizó entre junio y setiembre de 1998, en Immokalee, en el suroeste de Florida, en las instalaciones del Southwest Florida Research \& Education Center (SWFREC), que pertenece a la Universidad de Florida. Esta localidad está a $26^{\circ} 27^{\prime} \mathrm{N}, 8^{\circ} 26^{\prime} \mathrm{O}$ y $10 \mathrm{~m}$ de altitud.

Aunque se evaluaron las mismas variedades que en Turrialba, por la infraestructura disponible el diseño difirió, pues no se disponía de un invernadero suficientemente grande, sino de tres pequeños invernaderos de 3,6 x 7,2 m, con un techo de 2,4 $\mathrm{m}$ de altura en todos los costados. Los potes se ubicaron en el centro de cada uno de los invernaderos, con base en un diseño de cuadrado latino, para lo cual, se colocaron las plantas en seis hileras de seis plantas cada una.

Las plantas se sembraron en el respectivo invernadero y trasplantadas de manera individual en potes plásticos negros, cuadrados (12,5 x 12,5 x 12,5 cm), que contenían suelo esterilizado. Se sembraron en diferentes tiempos, según el hábito de crecimiento de cada especie, de manera que todas tuvieran al menos tres hojas verdaderas al momento de iniciarse el experimento. Fueron podadas según se necesitó, para estandarizarlas a una altura uniforme de $20 \mathrm{~cm}$. El área foliar $\left(\mathrm{cm}^{2}\right)$ de cada especie se obtuvo como un promedio, al medir una hoja de tres plantas de cada especie dentro de cada invernadero, para un total de nueve plantas, mediante un medidor de áreas.

Los adultos se recolectaron en col (Brassica oleracea var. acephala) var. Georgia, en el campo, mediante una aspiradora Dustbuster modificada, cuyo compartimiento de captura era un cilindro de poliestireno de $12 \mathrm{~cm}$ de longitud y $5 \mathrm{~cm}$ de diámetro. En cada uno se colocaron grupos de 300 individuos, que se transportaron en una hielera hasta los invernaderos, donde se liberaron, para un total de 1200 adultos por invernadero. Esto se hizo entre las 15:30-16:00 h la víspera del experimento, para lo cual en cada esquina se colocó un cilindro, a 1,2 m de altura.

Se registró el número de adultos en cada hospedante, entre 09:00-11:00 h, al día siguiente de liberados, así como dos días después. Esto se hizo volteando lentamente la tercera hoja de cada planta, de arriba hacia abajo, y contando todos los adultos posados en ella. El número total de adultos se dividió entre la superficie de la hoja, para convertirlo en un valor por $1 \mathrm{~cm}^{2}$ para cada especie, tras lo cual se multiplicó para obtener un valor estandarizado de adultos en $100 \mathrm{~cm}^{2}$. Dos semanas después, se tomó una hoja de cada planta, en la cual se contaron los huevos y ninfas presentes en una cuadrícula de $2 \mathrm{~cm}^{2}$, a los cuales se les dio seguimiento en cuanto a su desarrollo.

\section{Análisis estadístico}

Los datos se sometieron a un análisis de varianza y las medias fueron comparadas mediante la prueba de diferencias mínimas significativas (SAS Institute, 1985), con un nivel de significancia de 0,05. 


\section{Resultados}

En el experimento realizado en Turrialba, hubo cuatro grupos de tratamientos en cuanto a los números de adultos de $B$. tabaci. Un grupo estuvo representado por el tabaco, y otro por la berenjena, que mostraron los números más altos $(\mathrm{p}<0,01)$ (Cuadro 1). Fueron seguidos por el tomate y la vainica, que no difirieron entre sí, pero sí del pepino y el chile dulce, que mostraron los números más bajos. El número de adultos observado en el tabaco fue tan alto, que difirió $(\mathrm{p}<0,01)$ del resto de las Solanaceae (berenjena, tomate y chile dulce) (Cuadro 2), que son especies con cierta afinidad taxonómica.

En el experimento efectuado en Florida, los números de adultos en el tabaco fueron los más bajos de todos los hospedantes, aunque no difirieron ( $\mathrm{p}>0,05)$ del tomate, el chile dulce y el pepino a las $18 \mathrm{~h}$, ni tampoco de los dos primeros a las $66 \mathrm{~h}$ (Cuadro 3). Además, a las 66 h bajó el número de adultos en un factor de dos en el tabaco y el chile dulce, mientras que, subió en un factor casi equivalente en el tomate. Los hospedantes más preferidos por los

Cuadro 1. Número promedio de adultos de B.tabaci por planta, en los diferentes hospedantes. Centro Agronómico Tropical de Investigación y Enseñanza (CATIE), Turrialba, Costa Rica. Abril, 1998.

Table 1. Average number of B. tabaci adults per plant, on different hosts. Centro Agronómico Tropical de Investigación y Enseñanza (CATIE), Turrialba, Costa Rica. April, 1998.

\begin{tabular}{llll}
\hline Hospedante & N & \multicolumn{2}{c}{$\mathbf{X} \pm \mathbf{E E}$} \\
\hline Tabaco & 16 & $172,13 \pm 18,43$ & a \\
Berenjena & 16 & $85,25 \pm 10,33$ & b \\
Tomate & 16 & $53,06 \pm 8,75$ & cd \\
Vainica & 16 & $51,19 \pm 7,49$ & cd \\
Pepino & 16 & $43,38 \pm 5,34$ & d \\
Chile dulce & 16 & $38,38 \pm 6,73$ & d \\
\hline
\end{tabular}

Los promedios seguidos por la misma letra no fueron significativamente diferentes $(P=0,05) /$ Means indicated by the same letter are not significantly different $(\mathrm{P}=0.05)$.

EE: error estándar / EE: standard error.

Cuadro 2. Contrastes ortogonales para los números de adultos de B. tabaci en los diferentes hospedantes. Centro Agronómico Tropical de Investigación y Enseñanza (CATIE), Turrialba, Costa Rica. Abril, 1998.

Table 2. Orthogonal contrasts for numbers of B. tabaci adults on different hosts. Centro Agronómico Tropical de Investigación y Enseñanza (CATIE), Turrialba, Costa Rica. April, 1998.

\begin{tabular}{lccc}
\hline Contrastes & Cuadrado medio & F & Pr $>$ F \\
\hline Todos $v s$. tomate & 8333,33 & 7,00 & 0,0164 \\
Otras Solanaceae $v s$. tomate & 24865,75 & 20,90 & 0,0002 \\
Solanaceae $v s$. vainica & 16603,20 & 13,96 & 0,0015 \\
Solanaceae $v s$. pepino & 24587,57 & 20,67 & 0,0003 \\
Otras Solanaceae $v s$. tabaco & 153850,13 & 129,31 & 0,0001 \\
\hline
\end{tabular}


Cuadro 3. Número promedio de adultos de B. tabaci en los diferentes hospedantes (en $100 \mathrm{~cm}^{2}$ de superficie foliar), 18 y $66 \mathrm{~h}$ después de liberados. Southwest Florida Research \& Education Center (SWFREC), Immokalee, Florida, USA. Juniosetiembre, 1998.

Table 3. Average numbers of B. tabaci adults on $100 \mathrm{~cm}^{2}$ of leaf surface of each host plant, 18 y $66 \mathrm{~h}$ after release. Southwest Florida Research \& Education Center (SWFREC,) Immokalee, Florida, USA. June-September, 1998.

\begin{tabular}{|c|c|c|c|}
\hline & $18 \mathrm{~h}$ & $66 \mathrm{~h}$ & Promedio \\
\hline Vainica & 49,2 a & $41,0 \quad \mathrm{a}$ & $45,1 \quad \mathrm{a}$ \\
\hline Pepino & $18,6 \mathrm{abc}$ & $20,3 \quad b$ & $19,5 \mathrm{~b}$ \\
\hline Berenjena & $40,3 \mathrm{ab}$ & $45,7 \quad \mathrm{a}$ & $43,0 \quad \mathrm{a}$ \\
\hline Chile dulce & $21,3 \quad a b c$ & $9,7 \quad b c$ & $15,5 \quad b$ \\
\hline Tabaco & $4,9 \mathrm{c}$ & $2,8 \quad \mathrm{c}$ & $3,8 \quad b$ \\
\hline Tomate & $9,8 \quad \mathrm{c}$ & 16,4 bc & $13,1 \quad b$ \\
\hline
\end{tabular}

Los promedios seguidos por la misma letra no fueron significativamente diferentes $(\mathrm{P}=0,05)$ / Means indicated by the same letter are not significantly different $(\mathrm{P}=0.05)$.

adultos fueron la vainica y la berenjena, los cuales no difirieron entre sí ( $p>0,05)$, pero lo hicieron del resto de los tratamientos tanto a las $66 \mathrm{~h}$ como al considerar el promedio general; dichos tratamientos no difirieron entre sí en cuanto al promedio general.

Estas tendencias se mantuvieron para las formas inmaduras. En efecto, en el tabaco y el chile dulce se observaron menos huevos y ninfas de los dos tamaños o edades, en comparación con los demás hospedantes (Cuadro 4). En cuanto a los otros hospedantes, no hubo diferencias entre ellos, en relación con los huevos, pero sí con las ninfas pequeñas en vainica, en comparación con el pepino. Sin embargo, hubo mucho menos ninfas medianas en tabaco, chile dulce y vainica, seguidos por el tomate, pepino y berenjena. El número de ninfas grandes sumamente bajo en la vainica sugiere que el desarrollo del insecto era lento en este hospedante o, más aún, que muchas de ellas mueren antes de convertirse en adultos.

Cuadro 4. Número promedio de los estados inmaduros de $B$. tabaci (en $2 \mathrm{~cm}^{2}$ de cada planta hospedante), dieciséis días después de liberados los adultos. Southwest Florida Research \& Education Center (SWFREC), Immokalee, Florida, USA. Juniosetiembre, 1998.

Table 4. Average numbers of B. tabaci immature stages (on $2 \mathrm{~cm}^{2}$ of each host species), sixteen days after release. Southwest Florida Research \& Education Center (SWFREC), Immokalee, Florida, USA. June-September, 1998.

\begin{tabular}{|c|c|c|c|c|c|}
\hline & Huevos & Ninfas pequeñas & Ninfas medianas & Total de ninfas & Total de inmaduros \\
\hline Vainica & $1,4 \quad \mathrm{a}$ & 32,4 a & $1,7 \quad \mathrm{~d}$ & $34,1 \quad b$ & $35,5 \quad b$ \\
\hline Pepino & $1,4 \quad \mathrm{a}$ & $24,0 \quad \mathrm{~b}$ & $13,7 \quad b$ & $37,8 \quad b$ & $39,1 \quad b$ \\
\hline Berenjena & $1,3 \quad \mathrm{a}$ & $27,5 \mathrm{ab}$ & $21,1 \quad \mathrm{a}$ & $48,5 \quad \mathrm{a}$ & 49,9 a \\
\hline Chile dulce & $0,1 \quad b$ & $1,6 \mathrm{c}$ & $1,5 \mathrm{~d}$ & $3,1 \quad \mathrm{c}$ & $3,2 \mathrm{c}$ \\
\hline Tabaco & $0,1 \quad b$ & $0,2 \mathrm{c}$ & $0,3 \mathrm{~d}$ & $0,5 \mathrm{c}$ & $0,6 \mathrm{c}$ \\
\hline Tomate & $1,4 \quad b$ & $25,2 \quad a b$ & $9,6 \quad \mathrm{c}$ & $34,8 \quad b$ & $36,2 \quad b$ \\
\hline
\end{tabular}

Los promedios seguidos por la misma letra no fueron significativamente diferentes $(\mathrm{P}=0,05)$ / Means indicated by the same letter are not significantly different $(\mathrm{P}=0.05)$. 


\section{Discusión}

A escala mundial, hasta hoy no se cuenta con estudios comparativos en cuanto a la preferencia de diferentes biotipos de $B$. tabaci por distintos hospedantes (deseablemente de una misma variedad), en localidades agroecológicas contrastantes. Por tanto, para contribuir a subsanar esta carencia de información, se emprendió el presente trabajo comparativo, el cual permitió determinar que los biotipos New World (en Costa Rica) y MEAM1 (en Florida), mostraron diferencias en cuanto a su predilección, y esta preferencia diferencial por los cultivos hospedantes evaluados, podría obedecer a características biológicas propias de cada uno de los biotipos. Por ejemplo, se sabe que conforme el biotipo MEAM1 ha ido expandiendo su ámbito de distribución mundial, ha afectado cultivos que el biotipo New World no daña, entre los que sobresalen crucíferas como el repollo, la coliflor y el brócoli (Brassica oleracea), la lechuga (Lactuca sativa) y alfalfa (Medicago sativa) (Brown y Bird, 1992; Perring, 1996). El biotipo MEAM1 en Florida completó fácilmente su desarrollo en el cultivo de tomate y afectó de manera marginal al chile dulce, como se ha notado en esa localidad (Stansly, obs. pers.); mientras que, con el biotipo New World en Costa Rica ocurrió exactamente lo opuesto, pues no se desarrolló en el tomate, pero si profusamente en el chile dulce (Hilje, obs. pers.).

Hace tres decenios, cuando Greathead (1986) publicó la primera lista mundial de hospedantes de B. tabaci, aún no se conocía la existencia de tantos biotipos de este insecto, por lo que, en dicha lista podría estar implicado más de uno de estos. No obstante, en ella es llamativo el predominio de familias como Fabaceae (96 especies), Asteraceae (56) y Malvaceae, Solanaceae y Euphorbiaceae (32-35). Fue por esto que, para la presente investigación, se eligieron cultivos comúnmente sembrados en América Central y el Caribe, con énfasis en hortalizas, y que representaran a algunas de estas familias, como Solanaceae (tomate, chile dulce, berenjena y tabaco) y Fabaceae (vainica). También se incluyó Cucurbitaceae, pues en Costa Rica tanto el pepino como el melón y la sandía son muy apetecidas por B. tabaci (Hilje, obs. pers.); además, sobre el pepino había evidencias previas como cultivo trampa (Al-Musa, 1982) y actualmente, se sabe que el melón de tipo "cantaloupe" es preferido sobre el algodón por el biotipo MEAM1 (Castle, 2006).

En la presente investigación, al comparar los resultados de las preferencias de los dos biotipos evaluados, cabía la posibilidad de que la densidad de adultos y formas inmaduras registradas no fuera una respuesta a las características bioquímicas de cada hospedante, sino más bien del área foliar (tamaño y cantidad de hojas) disponible para ser colonizada por los insectos. Sin embargo, esto no ocurrió así. En Turrialba, los valores (adultos/ $\mathrm{cm}^{2}$ ) fueron los siguientes: vainica (142), tabaco (139), pepino (60), tomate (44), berenjena (39) y chile dulce (27). Por su parte, en Florida fueron: tomate (470), tabaco (329), pepino (245), berenjena (213), vainica (88) y chile dulce (56). Las diferencias entre ambas localidades obedecieron tanto al método de medición, que no es estrictamente comparable, como a la posible respuesta diferencial de las plantas a las respectivas condiciones climáticas, así como al tipo de suelo, fertilización y otros posibles factores desconocidos.

Si la preferencia se debiera al área foliar disponible, en Turrialba se habría esperado obtener números tan altos en la vainica como en el tabaco, pero en éste, dichos números fueron más que triplicados. En Florida fueron la berenjena y la vainica las especies preferidas por los adultos, pero sus valores de área foliar fueron intermedios o bajos; además, las formas inmaduras fueron más abundantes en la berenjena, el pepino, el tomate y la vainica, que no guardan la misma secuencia en cuanto al área foliar.

El caso más extremo es el tabaco, que en Florida presentó una mayor área foliar disponible, pero fue el menos preferido como hospedante, tanto de los adultos como de las formas inmaduras. No obstante, una posible explicación de su pobre colonización por B. tabaci, podría ser la profusa secreción de los tricomas glandulares de sus hojas, que no fue copiosa ni muy adhesiva en Turrialba, quizás por factores climáticos. Además, en Florida el tabaco fue colonizado con cierta presión por Myzus sp. (quizás M. nicotianae), al igual que las demás especies, excepto la vainica; en ellas, pareciera tratarse de M. persicae. 
Se podría argumentar que la fuente de insectos (tomate en Costa Rica y col en Florida) podría haber causado sesgos en los datos obtenidos, puesto que se ha demostrado que la exposición previa de B. tabaci a determinado hospedante puede condicionar la elección posterior de este (Van-Lenteren y Noldus, 1990). Sin embargo, en este caso el tomate ocupó la cuarta posición en la secuencia de preferencia en Costa Rica; la col (Cruciferae) utilizada como fuente en Florida, no tiene afinidad taxonómica con ninguno de los cultivos evaluados.

En términos de aplicabilidad, se propone evaluar en campos de agricultores la utilidad de los hospedantes estudiados más promisorios como cultivos trampa asociados con el tomate. En el caso de Costa Rica, el tabaco y la berenjena serían los mejores candidatos. Sin embargo, debe tenerse en cuenta que el tabaco tiene otro tipo de restricciones, pues en ciertas zonas productoras de tomate y aptas para la siembra de tabaco hay prohibiciones sanitarias para sembrarlo, para desfavorecer la incidencia y diseminación del moho azul del tabaco (Peronospora tabacina).

Por su parte, en Florida, tanto la berenjena como la vainica podrían funcionar como cultivos trampa, aunque Tsai y Wang (1996), al comparar la respuesta de B. argentifolii (o biotipo MEAM1) a varios hospedantes en cuanto a algunos parámetros reproductivos, determinaron que la berenjena fue el cultivo más apto, en contraste con la vainica; el tomate, camote y pepino ocuparon posiciones intermedias. Esto pareciera contradecir los hallazgos de la presente investigación, pero, aparte de que la variedad (Podsquad) fue diferente, debe considerarse que los experimentos de ellos no fueron de escogencia.

A pesar de sus diferencias, los biotipos New World y MEAM1, coincidieron en su fuerte y significativa preferencia por la berenjena; eventualmente, convendría evaluar si también lo es para el biotipo MED, ya que no había ingresado a Florida ni a Costa Rica cuando se efectuó este estudio. Si este último biotipo también mostrara una fuerte preferencia por la berenjena, esta podría utilizarse como cultivo trampa en aquellos sistemas de producción en los que coexistan dos o más de estos biotipos. Por tanto, de ser así, convendría evaluar la utilización de la berenjena en el campo como cultivo trampa, oportunamente tratada con un insecticida sistémico o, deseablemente, con un mico-insecticida, para que los adultos de $B$. tabaci que se aproximen a esas estructuras sean atraídos y mueran en el cultivo trampa. Sin embargo, habría que considerar los siguientes aspectos:

En primer lugar, la berenjena tendría que mantenerse suficientemente atractiva durante el período crítico del tomate a los virus, lo cual no debería ser un problema para variedades de tomate determinadas, de ciclo corto, pero sí para las de crecimiento indeterminado. En este último caso, la atracción de la berenjena podría perderse debido a su senescencia, o a un fuerte ataque de $B$. tabaci, aunque esto último podría controlarse con aplicaciones periódicas de un insecticida sistémico o el mico-insecticida elegido. Obviamente, debería removerse además, de manera puntual y oportuna, para descartar el riesgo de que, ya abandonado tras cumplir su función, pudiera convertirse en una fuente de la plaga.

En segundo lugar, es importante demostrar de manera fehaciente que la berenjena no actúe como reservorio de ninguno de los begomovirus que afectan al tomate. Sin embargo, aun cuando lo fuera, como los individuos de B. tabaci morirían al alimentarse en ella, aunado al hecho de ser un cultivo tan solo temporal; por lo que sería destruido una vez que cumpla su función, esto evitaría o reduciría considerablemente el riesgo de convertirse en una fuente de inóculo de virus para el tomate.

En tercer lugar, en cuanto al arreglo espacial del cultivo trampa, lo lógico sería intercalar la berenjena dentro de la parcela de tomate, pero esto tendría repercusiones agronómicas y económicas. En tal sentido, al tener que sustituir hileras de tomate por las de berenjena, se sacrificaría parte de la producción de tomate, además de que se complicaría la logística de su manejo agronómico, al tener que atender dos cultivos con diferentes requerimientos, ciclos de vida y fenología. Esto se justificaría si solo esta táctica de manejo fuera realmente rentable. Sin embargo, para obviar esta limitación, una opción sería sembrar la berenjena alrededor de la parcela de tomate o solamente en los costados por donde más inciden las corrientes de viento (Hilje y Stansly, 2017), que son las que acarrean a los adultos (Blackmer y Byrne, 1993; Byrne y Blackmer, 1996). 
Estas preocupaciones no son aplicables para sistemas de ambientes protegidos, de gran auge en la actualidad tanto en Costa Rica, como en Florida y otras regiones del mundo. La berenjena podría sembrarse en una o dos hileras en los costados de los invernaderos donde predomina y más fluye el viento, de modo que se convertiría en un sumidero, al retener y matar los adultos ahí, y así reduciría la población de B. tabaci. Además, este enfoque podría ser implementado no solo para invernaderos donde se produce tomate, sino que también para aquellos donde se siembran otras hortalizas.

\section{Conclusiones}

Los biotipos New World (en Costa Rica) y MEAM1 (en Florida) mostraron una preferencia diferencial por sus hospedantes. Así, el primero prefirió al tabaco, seguido por la berenjena, el tomate y la vainica, mientras que, el pepino y el chile dulce fueron los menos preferidos. Por su parte, el segundo prefirió a la vainica y la berenjena, seguido por el pepino, el chile dulce y el tomate, en tanto que el tabaco fue el menos preferido, pero quizás por la influencia de factores exógenos. No obstante, a pesar de estas diferencias, ambos biotipos exhibieron una fuerte y significativa preferencia por la berenjena, lo cual abre la posibilidad para su utilización como cultivo trampa, especialmente en tomate y otras hortalizas sembradas en ambientes protegidos. Este es un paso previo a su potencial validación en el campo y su utilización como cultivos trampa por parte de los productores de tomate.

\section{Agradecimientos}

Los autores expresan su agradecimiento a Douglas Cubillo ( $\dagger$ ), Guido Sanabria y Arturo Ramírez (CATIE), y James M. Conner (SWFREC), por su apoyo en los experimentos o en los análisis estadísticos. A Natalia Barboza (Universidad de Costa Rica), el aporte de información sobre begomovirus en Costa Rica. Al CATIE, la Universidad de Florida y el Departamento de Agricultura de los EE.UU., por el financiamiento de esta investigación.

\section{Literatura citada}

Ahohuendo, B.C., and S. Sarkar. 1995. Partial control of the spread of African Cassava Mosaic Virus in Benin by intercropping. J. Plant Dis. Prot. 102:249-256.

Al-Musa, A. 1982. Incidence, economic importance, and control of Tomato Yellow Leaf Curl in Jordan. Plant Dis. 66:561-563. doi:10.1094/PD-66-561

Anderson, P.K., and F.J. Morales, editors. 2005. Whitefly and whitefly-borne viruses in the tropics: Building a knowledge base for global action. CIAT, COL.

Arias, R., y L. Hilje. 1993. Uso del frijol como cultivo trampa y de un aceite agrícola para disminuir la incidencia de virosis transmitida por Bemisia tabaci (Gennadius) en el tomate. Man. Integ. Plagas 27:27-35.

Barboza, N., M. Blanco-Meneses, M. Hallwass, E. Moriones, and A.K. Inoue-Nagata. 2014. First report of Tomato yellow leaf curl virus in tomato in Costa Rica. Plant Dis. 98:699. doi:10.1094/PDIS-08-13-0881-PDN

Blackmer, J.L., and D.N. Byrne. 1993. Flight of Bemisia tabaci in a vertical flight chamber: Effect of time of day, sex, age and host quality. Physiol. Entomol. 18:223-232. doi:10.1111/j.1365-3032.1993.tb00592.x

Boykin, L.M. 2014. Bemisia tabaci nomenclature: lessons learned. Pest Manag. Sci. doi:10.1002/ps.3709 
Brown, J.K., and J. Bird. 1992. Whitefly transmitted geminiviruses in the Americas and the Caribbean Basin: past and present. Plant Dis. 76:220-225. doi:10.1094/PD-76-0220.

Brown, J.K., F.M. Zerbini, J. Navas-Castillo, E. Moriones, R. Ramos-Sobrinho, J.C.F. Silva, E. Fiallo-Olivé, R.W. Briddon, C. Hernández-Zepeda, A. Idris, V.G. Malathi, D.P. Martin, R. Ribera-Bustamante, S. Ueda, and A. Varsani. 2015. Revision of Begomovirus taxonomy based on pairwise sequence comparisons. Arch. Virol. doi:10.1007/s00705-015-2398

Byrne, D.N., and J.L. Blackmer. 1996. Examination of short-range migration by Bemisia tabaci. En: D. Gerling, and R.T. Mayer, editors, Bemisia 1995: taxonomy, biology, damage, control and management. Intercept, GBR. p. 17-28.

Castle, S.J. 2006. Concentration and management of Bemisia tabaci in cantaloupe as a trap crop for cotton. Crop Prot. 25:574-584. doi:10.1016/j.cropro.2005.08.013

De-Barro P.J., S.S. Liu, L.M. Boykin, and A.B. Dinsdale. 2011. Bemisia tabaci: A statement of species status. Ann. Rev. Entomol. 56:1-19. doi:10.1146/annurev-ento-112408-085504

Fargette, D., and C. Fauquet. 1988. A preliminary study on the influence of intercropping maize and cassava on the spread of African cassava mosaic virus by whiteflies. Aspects Appl. Biol. 17:195-202.

Greathead, A.H. 1986. Host plants. En: M.J.W. Cock, editor, Bemisia tabaci A literature survey. CAB, and International Institute of Biological Control, Silwood Park, GBR.p. 17-26.

Hernández, E., J.A. Guevara, J.A. Vargas, y M.P. Ramírez. 2014. Moscas blancas como vectores de virus en Costa Rica. En: N. Barboza et al., editores, Caracterización, epidemiología y manejo del complejo moscas blancas-virus en sistemas hortícolas de Costa Rica. EUNED, San José, CRC. p. 29-44.

Hilje, L., y P. Stansly. 2017. Dificultades metodológicas en la selección de cultivos trampa para el manejo del complejo Bemisia tabaci-virus en tomate. Rev. Cienc. Amb.51(1):76-91.

Hilje, L., H.S. Costa, and P.A. Stansly. 2001. Cultural practices for managing whiteflies and associated viral diseases. Crop Prot. 20:801-812. doi:10.1016/S0261-2194(01)00112-0

Hokkanen, H.M.T. 1991. Trap cropping in pest management. Ann. Rev. Entomol. 36:119-138. doi:0066-4170/9110101-0119\$02.00

Jovel, J., C. Kleinn, V. Cartín, B. Valverde, and L. Hilje. 2000. Movimientos diarios de Bemisia tabaci en parcelas de tomate, en Turrialba, Costa Rica. Man. Integ. Plagas 55:49-55.

Lefeuvre P., D.P. Martin, G. Harkins, P. Lemey, A.J. Gray, S. Meredith, F. Lakay, A. Monjane, J.M. Lett, A. Varsani, and J. Heydarnejad. 2010. The spread of Tomato Yellow Leaf Curl Virus from the Middle East to the World. PLoS Pathog 6:e1001164. doi:10.1371/journal.ppat.1001164

McKenzie, L., G. Hodges , L.S. Osborne, F.J. Byrne, and R.G. Shatters Jr. 2009. Distribution of Bemisia tabaci (Hemiptera: Aleyrodidae) biotypes in Florida - investigating the Q invasion. J. Econ. Entomol. 102:670-676. doi:10.1603/029.102.0227

Morales, F.J., L. Hilje, J. Vallejos, G. Sibaja, C. Araya, and R. Araya. 2005. Costa Rica. In: P.K. Anderson, and F.J. Morales, editors, Whitefly and whitefly-borne viruses in the tropics: Building a knowledge base for global action. CIAT, COL. p. $217-221$.

Peralta, L., y L. Hilje. 1993. Un intento de control de Bemisia tabaci con insecticidas sistémicos incorporados a la vainica como cultivo trampa, más aplicaciones de aceite en el tomate. Man. Integ. Plagas 30:21-23.

Perring, T.M. 1996. Biological differences of two species of Bemisia that contribute to adaptive advantage. In: D. Gerling, and R.T. Mayer, editors, Bemisia 1995: Taxonomy, biology, damage, control and management. Intercept, GBR. p. 1-16.

SAS Institute. 1985. Guide for personal computers. Version 6 ed. SAS Institute Inc, Cary, NC, USA.

Schuster, D.J. 2004. Squash as a trap crop to protect tomato from whitefly-vectored yellow leaf curl. Int. J. Pest Manag. 50:281-284. doi:10.1080/09670870412331284591 
Schuster, D.J., P.A. Stansly, and J.E. Polston. 1996. Expressions of plant damage of Bemisia. In: D. Gerling, and R.T. Mayer, editors, Bemisia 1995: Taxonomy, biology, damage control and management. Andover, Hants, GBR. p. 153-165.

Shelton, A.M., and F.R. Badenes-Perez. 2006. Concepts and applications of trap cropping in pest management. Ann. Rev. Entomol. 51:285-308. doi:10.1146/annurev.ento.51.110104.150959

Smith, H.A., R.L. Koenig, H.J. McAuslane, and R. McSorley. 2000. Effect of silver reflective mulch and a summer squash trap crop on densities of immature Bemisia argentifolii (Homoptera: Aleyrodidae) on organic bean. J. Econ. Entomol. 93:726-731.

Smith, H.A., and R. McSorley. 2000. Potential of field corn as a barrier crop and eggplant as a trap crop for management of Bemisia argentifolii (Homoptera: Aleyrodidae) on common bean in North Florida. Florida Entomol. 83:145-158.

Tsai, J.H., and K.H. Wang. 1996. Development and reproduction of Bemisia argentifolii (Homoptera: Aleyrodidae) on five host plants. Environ. Entomol. 25:810-816. doi: 10.1093/ee/25.4.810

Van-Lenteren, J.C., and L.P.J. Noldus. 1990. Whitefly-plant relationships: Behavioural and ecological aspects. En: D. Gerling, editor, Whiteflies: Their bionomics, pest status and management. Athenaeum Press, New Castle, GBR. p. 47-89. 